\title{
Taxonomic study of the genus Lateantenna Amsel, 1968 (Lepidoptera: Blastobasidae) from Mainland China, with descriptions of four new species
}

\author{
Kaijian Teng \& Shuxia Wang*
}

Teng, K. \& Wang, S. 2019: Taxonomic study of the genus Lateantenna Amsel, 1968 (Lepidoptera: Blastobasidae) from Mainland China, with descriptions of four new species. — Entomol. Fennica 30: 1-19. https://doi.org/10.33338/ ef.79901

The ten species of the genus Lateantenna Amsel, 1968 known from China are reviewed. Four new species are described: L. semicircularis $\mathbf{s p .}$. n. and L. zhejiangensis sp. n. from Zhejiang, L. lunata sp. n. from Yunnan and Hainan, and $L$. triangulata sp. n. from Yunnan. Lateantenna eurotella (Adamski, 2010) and $L$. ianella (Adamski, 2003) are newly recorded for China. The females of $L$. camelliae (Chen \& Wu, 2013) and L. ianella (Adamski, 2003) are described for the first time. Photographs of adults and genitalia are provided. Based on male genitalia, a key to the species of Mainland China is provided. Two maps showing the distribution of these species are also included.

K. Teng \& S. Wang, College of Life Sciences, Nankai University, Tianjin 300071, P.R. China. *Correspondingauthor'se-mail:shxwang@nankai.edu.cn.Kaijian Teng's e-mail:kaijianjn@163.com

Received 28 November 2017, accepted 23 March 2018

\section{Introduction}

The family Blastobasidae (Lepidoptera, Gelechioidea) includes more than 500 species in 23 genera worldwide (Sinev 2014). The blastobasid fauna of China is one of the least known (Adamski \& Li 2010), with just 16 species in five genera reported (Chen et al. 2013, Ohshima 2013, Sinev 2014).

Lateantenna was established by Amsel (1968), based on its type species L. fuscella Amsel, 1968. Sinev (2014) transferred 28 species from four genera (Calosima Dietz, 1910, Blastobasis Zeller, 1855, Neoblastobasis Kuznetzov \& Sinev, 1985, and Opogona Zeller, 1853) to Lateantenna. Park and Adamski (2017) transferred Neoblastobasis songi Park, 2014 to Lateantenna, and treated it as a junior synonym of L. eurotella (Adamski, 2010). Ohshima et al.
(2018) transfered Lateantenna inana (Butler, 1881) and L. scotia (Turner, 1947) from Blastobasis. Prior to this study, Lateantenna included 31 known species worldwide, distributed in the $\mathrm{Pa}$ laearctic (Azerbaijan, China, Georgia, Japan, Korea, Pakistan, Russia, United Arab Emirates), Oriental (China, India, Sri Lanka, Thailand, Vietnam), Australian (Australia, New Caledonia, Tasmania) and Ethiopian (Congo, Kenya, Seychelles) regions. Host plants of several Lateantenna species are known (Table 1).

Five Lateantenna species have been recorded from China before this study. Lateantenna brevicornis (Moriuti, 1987), L. decolor (Meyrick, 1907) and L. spiniharpella (Kuznetzov \& Sinev, 1985) have been recorded only from Taiwan (Heppner 1992, Ohshima 2013); L. spermologa (Meyrick, 1916) is distributed in Hong Kong (bred in Australia from garlic imported from 
Table 1. Host plants of thirteen Lateantenna species. The three species with an asterisk $\left(^{*}\right)$ have been recorded from Mainland China.

\begin{tabular}{|c|c|c|c|}
\hline Lateantenna species & Plant species & Damaged parts & Reference $^{\#}$ \\
\hline \multirow{5}{*}{$\begin{array}{l}{ }^{*} \text { L. } \text { decolor } \\
\text { (Meyrick, 1907) }\end{array}$} & Fabaceae & & \\
\hline & $\begin{array}{l}\text { Tamarindus indicus L. } \\
\text { Moraceae }\end{array}$ & Refuse in fork of the tree & 1 \\
\hline & $\begin{array}{l}\text { Ficus racemosa } \mathrm{L} . \\
\text { Rutaceae }\end{array}$ & Fruits & 1 \\
\hline & $\begin{array}{l}\text { Citrus unshiu Marc. } \\
\text { Ebenaceae }\end{array}$ & pedicel of fruits & 2 \\
\hline & Diospyros kaki Thunberg & living bark tissue & 2 \\
\hline \multirow{11}{*}{$\begin{array}{l}\text { L. inana } \\
\quad \text { (Butler, 1881) } \\
\text { L. spermologa } \\
\quad \text { (Meyrick, 1916) }\end{array}$} & Rutaceae & & \\
\hline & Citrus unshiu Marc. & pedicel of fruits & 2 \\
\hline & Amaryllidaceae & & \\
\hline & $\begin{array}{l}\text { Allium sativum } \mathrm{L} \text {. } \\
\text { Theaceae }\end{array}$ & Bulbs (dried, smoked) & 3 \\
\hline & Camellia sinensis (L.) & Seeds & 4 \\
\hline & Dipterocarpaceae & & \\
\hline & Shorea robusta Roth & Seeds, Fruits & 4 \\
\hline & Dipterocarpus turbinatus. C. F. Gaertn. & Seeds, Fruits & 4 \\
\hline & $\begin{array}{l}\text { D. obtusifolius Teijsm. ex Miq. } \\
\text { Annonaceae }\end{array}$ & Seeds, Fruits & 4 \\
\hline & $\begin{array}{l}\text { Polyalthia longifolia (Sonn.) } \\
\text { Moraceae }\end{array}$ & Seeds & 4 \\
\hline & Ficus racemosa $\mathrm{L}$. & Seeds, Fruits & 4 \\
\hline \multirow{3}{*}{$\begin{array}{l}\text { L. crassifica } \\
\text { (Meyrick, 1916) }\end{array}$} & Fabaceae & & \\
\hline & $\begin{array}{l}\text { Crotalaria juncea L. } \\
\text { Dipterocarpaceae }\end{array}$ & Pods, Seeds & 4 \\
\hline & Shorea robusta Roth & Seeds, Fruits, Leaves & 4 \\
\hline \multirow{2}{*}{$\begin{array}{l}\text { L. curta } \\
\text { (Meyrick, 1916) }\end{array}$} & Rubiaceae & & \\
\hline & Coffea quillon Wester & & 4 \\
\hline \multirow{2}{*}{$\begin{array}{l}\text { L. molinda } \\
\text { (Meyrick, 1925) }\end{array}$} & Dipterocarpaceae & & \\
\hline & Shorea robusta Roth & Seeds, Fruits, Leaves & 4 \\
\hline \multirow{9}{*}{$\begin{array}{l}\text { L. ochromorpha } \\
\text { (Meyrick, 1925) }\end{array}$} & Dipterocarpaceae & & \\
\hline & Shorea robusta Roth & Seeds, Fruits, Leaves & 4 \\
\hline & $\begin{array}{l}\text { Dipterocarpus baudii Korth. } \\
\text { Amaryllidaceae }\end{array}$ & Fruits & 4 \\
\hline & Allium ascalonicum L. & & 4 \\
\hline & A. sativum $\mathrm{L}$. & & 4 \\
\hline & Theaceae & & \\
\hline & Camellia sinensis (L.) & & 4 \\
\hline & Palmae & & \\
\hline & Elaeis guineensis Jacq. & & 4 \\
\hline \multirow{3}{*}{$\begin{array}{l}{ }^{*} \text { L. spiniharpella } \\
\quad \text { (Kuznetzov \& Sinev, 1985) }\end{array}$} & Amaryllidaceae & & \\
\hline & $\begin{array}{l}\text { Allium sativum } \mathrm{L} \text {. } \\
\text { Fagaceae }\end{array}$ & Bulbs & 1 \\
\hline & Quercus serrata Thunberg & Acorns, Fallen leaves & 5 \\
\hline \multirow{2}{*}{$\begin{array}{l}\text { L. millicentae } \\
\text { (Adamski, 2010) }\end{array}$} & Chrysobalanaceae & & \\
\hline & Hirtella zanzibarica Oliv. & Fruits & 6 \\
\hline \multirow{3}{*}{$\begin{array}{l}\text { L. perisella } \\
\quad \text { (Adamski, 2010) }\end{array}$} & Linaceae & & \\
\hline & $\begin{array}{l}\text { Hugonia castaneifolia Engl. } \\
\text { Olacaceae }\end{array}$ & Fruits & 6 \\
\hline & Ximenia caffra Sond. & Fruits & 6 \\
\hline \multirow{2}{*}{$\begin{array}{l}\text { L. wangithiae } \\
\text { (Adamski, 2010) }\end{array}$} & Apocynaceae & & \\
\hline & Pleiocarpa pycnantha (K. Schum.) & Fruits & 6 \\
\hline \multirow{3}{*}{$\begin{array}{l}\text { L. ximeniaella } \\
\quad \text { (Adamski, 2010) }\end{array}$} & Olacaceae & & \\
\hline & $\begin{array}{l}\text { Ximenia caffra Sond. } \\
\text { Clusiaceae }\end{array}$ & Fruits & 6 \\
\hline & Calophyllum inophyllum L. & Fruits & 6 \\
\hline \multirow{2}{*}{$\begin{array}{l}\text { *L. camalliae } \\
\quad(\text { Chen \& Wu, 2013) }\end{array}$} & Theaceae & & \\
\hline & Camellia oleifera Abel & Seeds & 7 \\
\hline
\end{tabular}

\#) References: 1. Moriuti 1987, 2. Ohshima et al. 2018, 3. Meyrick 1916, 4. Robinson et al.2010, 5. Ohshima 2013, 6. Adamski et al.2010, 7. Chen et al. 2013 
Fig. 1. Distribution of Lateantenna spp. in China.

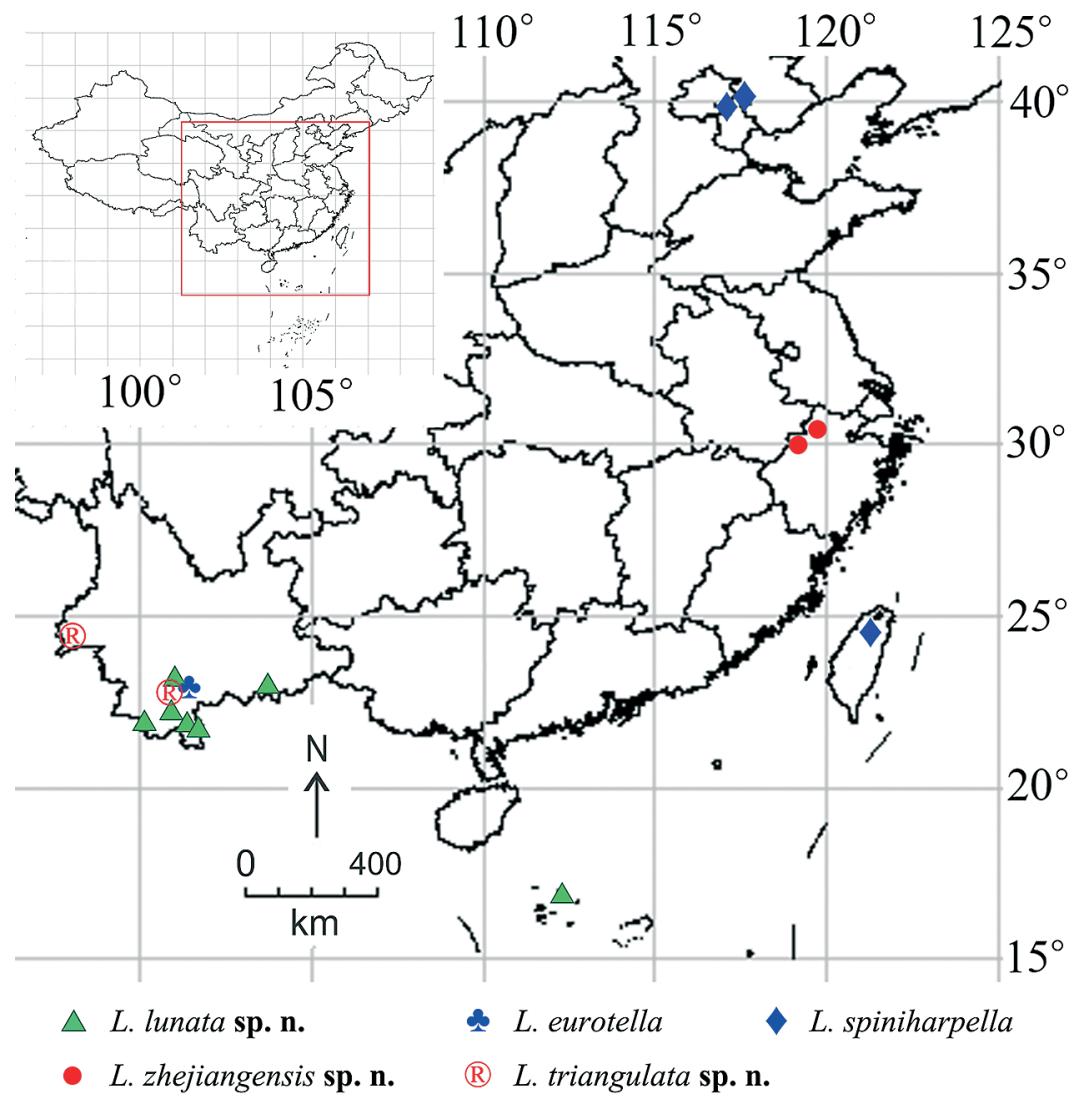

Hong Kong) and Taiwan (Heppner 1992), which is not available in the present study; and $L$. camelliae (Chen \& Wu, 2013) has been recorded from Mainland China.

The objective of this study is to review the ten species of Lateantenna from Mainland China, including the descriptions of four new species. Two maps are provided to show the distributions of the ten Lateantenna species in China (Figs. 1,2).

\section{Materials and methods}

The specimens examined in this study were collected from mountains, botanical gardens, and nature reserves in China by using light traps. The genitalia dissections were carried out following the methods introduced by Li (2002). Photographs of adults were taken with a Leica stereo microscope M205A plus Leica Application Suite 4.2 software, and genitalia were captured using a Leica DM750 microscope plus the same software as for adults. Terminology mostly follows Adamski and Brown (1989). We use the term "sacculus" to refer to the reflexed, broadened or sclerotized ventral area of the lower division of the valva.

All specimens studied, including the types, are deposited in the Insect Collection of Nankai University, Tianjin, China (NKU).

\section{Taxonomy}

\subsection{Genus Lateantenna Amsel, 1968}

Lateantenna Amsel, 1968: 19.

Type species. Lateantenna fuscella Amsel, 1968, by monotypy.

Diagnosis. Lateantenna is characterized by the combination of the following features: the first flagellomere of antenna is dilated and notched (Fig. 3a) in male, the forewing usually 


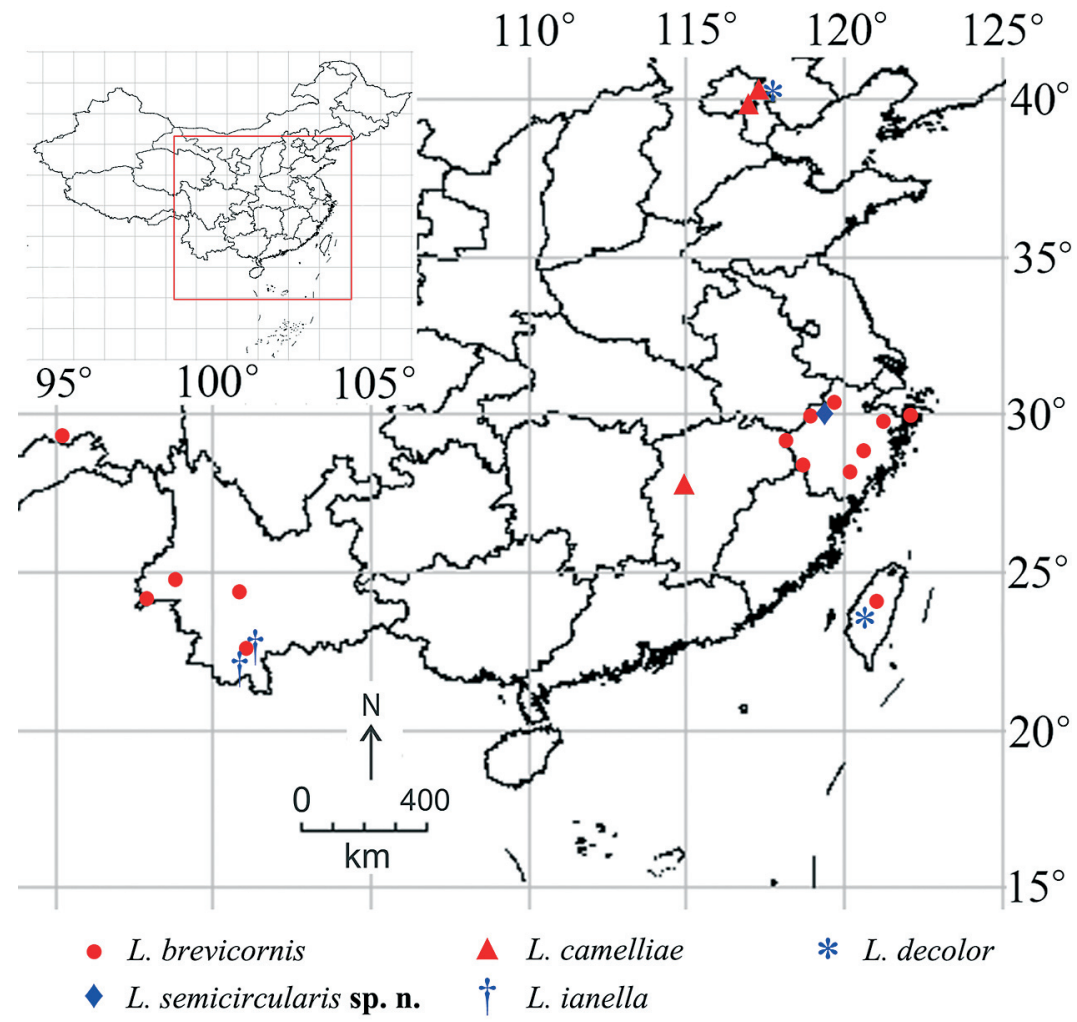

Fig. 2. Distribution of Lateantenna spp. in China. has distinct discal, discocellular and tornal spots (Figs. 4, 5), $\mathrm{M}_{2}$ and $\mathrm{M}_{3}$ of the hindwing is coincident and stalked with $\mathrm{CuA}_{1}$ (Fig. 3b); the sacculus of the valva has a basal spine-like projection, the anellus bears cone-like setae and the signum is horn-shaped, with a dilated basal plate.

Lateantenna is similar to Neoblastobasis Kuznetzov \& Sinev, 1985 in appearance, but it can be distinguished by the sacculus of the valva having a basal spine-like projection in the male genitalia, which is absent in Neoblastobasis.

\subsection{Species descriptions}

3.2.1. Lateantenna zhejiangensis Teng \& Wang, sp. n. (Figs. 4a, 6a, 8a-c)

Type material. China: Zhejiang Province: Holotype: ${ }^{\top}$, Laoan $\left(30.33^{\circ} \mathrm{N}, 119.40^{\circ} \mathrm{E}\right)$, Mt. Tianmu, 555 m, 17.VIII.2014, Aihui Yin, Qingyun Wang and Suran Li leg., slide No. TKJ17212. Paratypes: $181 \hat{\jmath}, 75 \circ$, same data as holotype except dated 16.-19.VIII.2014; 2へ, Sanmuping,
Mt. Tianmu, 789 m, 13.-14.VII. 2014, Aihui Yin, Xuemei $\mathrm{Hu}$ and Qingyun Wang leg.; 14へ, 3 , Sanmuping, Mt. Tianmu, $789 \mathrm{~m}, 10 .-11$. VIII. 2014, Aihui Yin, Qingyun Wang and Suran Li

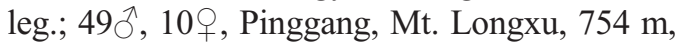
23.-26.VIII.2014, Aihui Yin, Qingyun Wang and

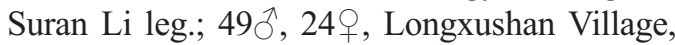
Mt. Longxu, 778 m, 20.-22.VIII.2014, Aihui

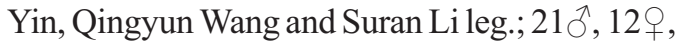
Jiufu Village, Mt. Longtang, 520 m, 27.-31.VIII. 2014, Aihui Yin, Qingyun Wang and Suran Li leg.

Diagnosis. Lateantenna zhejiangensis sp. n. is similar to L. spiniharpella (Kuznetzov \& Sinev, 1985) and L. brevicornis (Moriuti, 1987) in the male genitalia. It can be separated from $L$. spiniharpella and L. brevicornis by the upper division of the valva having basal $2 / 5$ heavily sclerotized ventrally and forming a narrow band while the upper division of the valva is not sclerotized ventrally in the latter two species. It can be further separated by the lower division of the valva with distal $1 / 5$ sharply produced to a acutely-curved apical process, and the basal 


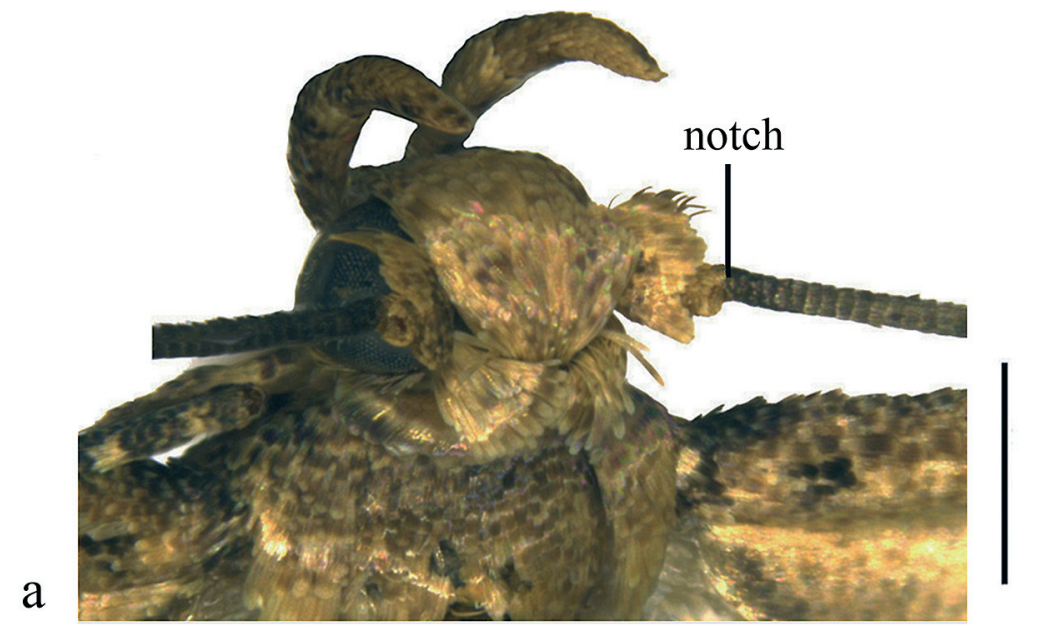

Fig. 3. Morphology of Lateantenna spp. - a. Head of $L$. lunata sp. n., holotype $\delta$. - b. Venation of $L$. triangulata sp. n., paratype $\hat{\partial}$, slide No. TKJ17303W. Scale bars: $0.5 \mathrm{~mm}$.

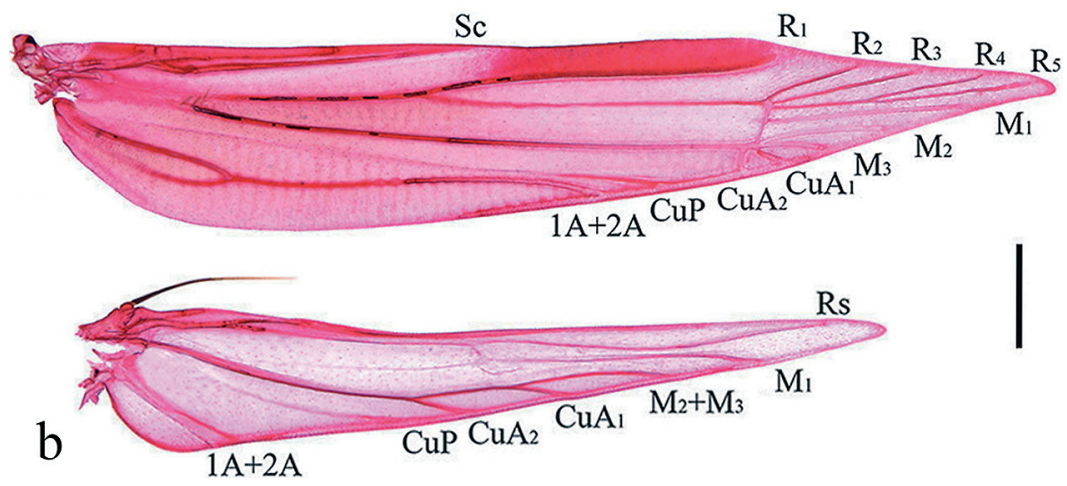

spine-like projection reaching distal $2 / 5$ of the valva (Fig. 6a); in L. spiniharpella, the distal $1 / 5$ of the lower division of the valva produces triangularly to a point, and the basal spine-like projection reaches distal $1 / 6$ of the valva (Fig. 6b); in L. brevicornis the distal $2 / 7$ of the lower division of the valva suddenly produces to a slender spinelike process, and the basal spine-like projection reaches distal 3/7 of the valva (Fig. 6c).

Description. Adult (Fig. 4a) forewing length 4.0-5.5 $\mathrm{mm}(n=440)$. Head greyish brown or pale greyish brown, scales tipped with greyish white. Antenna with scape brown or greyish brown, scales tipped with greyish white, usually becoming pale yellow or pale greyish white on dorsal surface, pale yellow on ventral surface; pecten brown; flagellum dark brown, ciliated on ventral surface in male, first flagellomere dilated, forming a notch in male. Labial palpus with outer surface dark brown, mixed with scales tipped with greyish white, inner surface pale greyish brown, but mixed with scales tipped with greyish white in female; second segment greyish white apically; third segment slightly shorter than second, distal half gradually narrowed to blunt apex, in male with a pale yellow crescent patch on inner surface. Labial palpus in female narrower than in male; third segment gradually narrowed from base to pointed apex. Haustellum brown. Mesonotum and tegula brown, with scattered pale greyish brown scales, intermixed with scales tipped with pale greyish white or pale yellow. Forewing brown, scales tipped with greyish white, paler on basal 1/3 except dark brown at proximal base; discal, discocellular and tornal spots black; submedian fascia dark brown, its outer margin obscure, inner margin edged with pale grey scales tipped with greyish white, medi- 

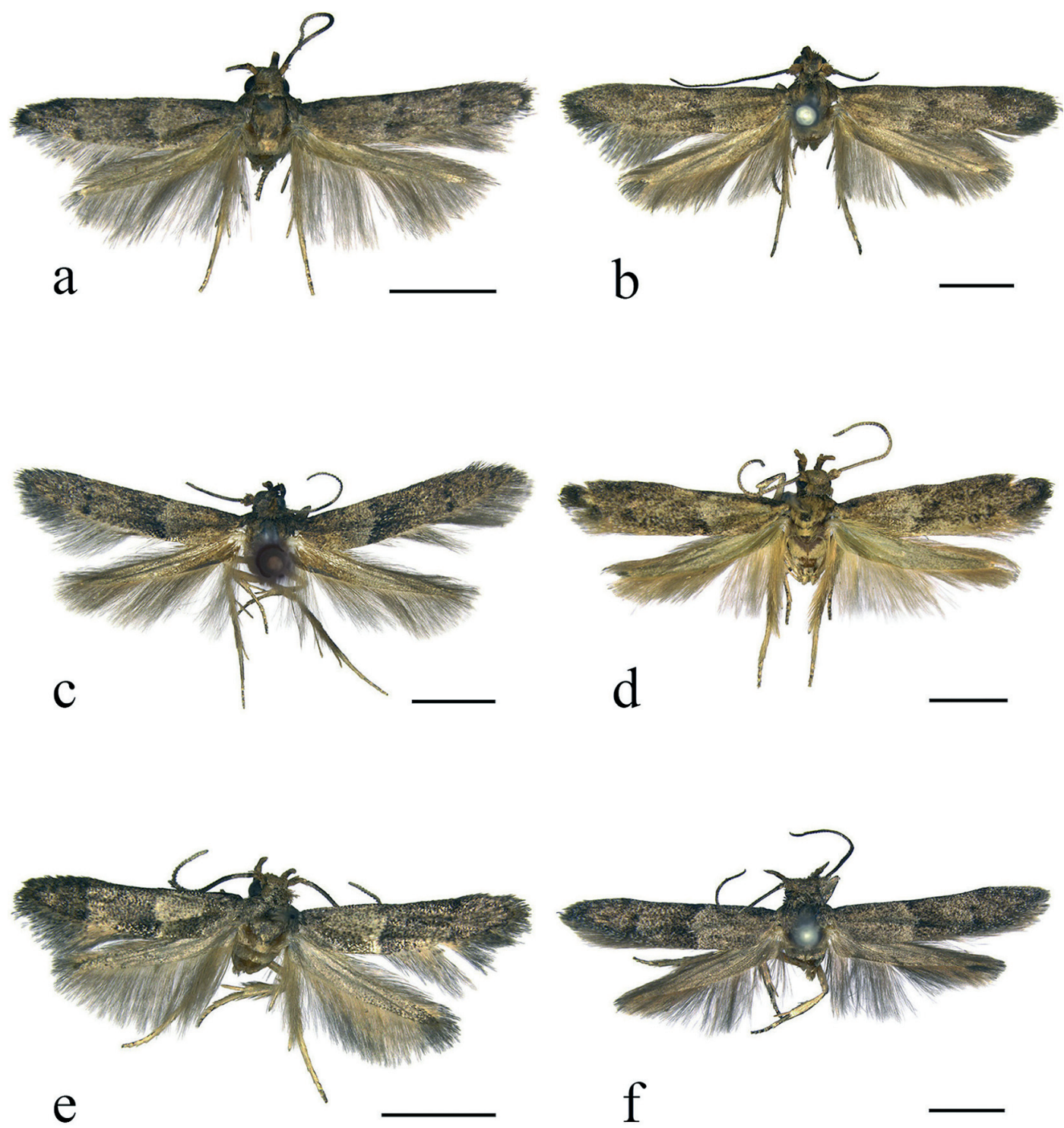

Fig. 4. Male adults of Lateantenna spp. - a. L. zhejiangensis sp. n., holotype. - b. L. spiniharpella. - c. L. brevicornis. - d. L. decolor. - e. L. semicircularis sp. n., holotype. - f. L. camelliae. Scale bars: $2.0 \mathrm{~mm}$.

ally curved sub-triangularly outward to discal spot; fringe greyish brown, intermixed with brown and greyish brown scales tipped with greyish white. Hindwing and fringe pale greyish brown, becoming darker from base to apex. Legs dark brown and with brown scales tipped with greyish white on ventral surface, greyish white on dorsal surface; tarsomeres of hindleg greyish white apically.

Male genitalia (Fig. 6a). Uncus slightly curved ventrad, sparsely setose, broad at base, narrowed to basal $1 / 3$, parallel-sided medially, thereafter slightly narrowed to rounded apex. Gnathos sub-quadrate, posterior margin slightly convex, bearing two small dentitions medially, anterior margin slightly concave medially. Valva with upper division broad at base, narrowed to basal $2 / 5$, with microtrichiae becoming denser from base to basal $2 / 5$, basal $2 / 5$ heavily sclerotized ventrally and forming a narrow band, distal $3 / 5$ gradually dilated to rounded and setose apex. Lower division of valva with basal $3 / 5$ 

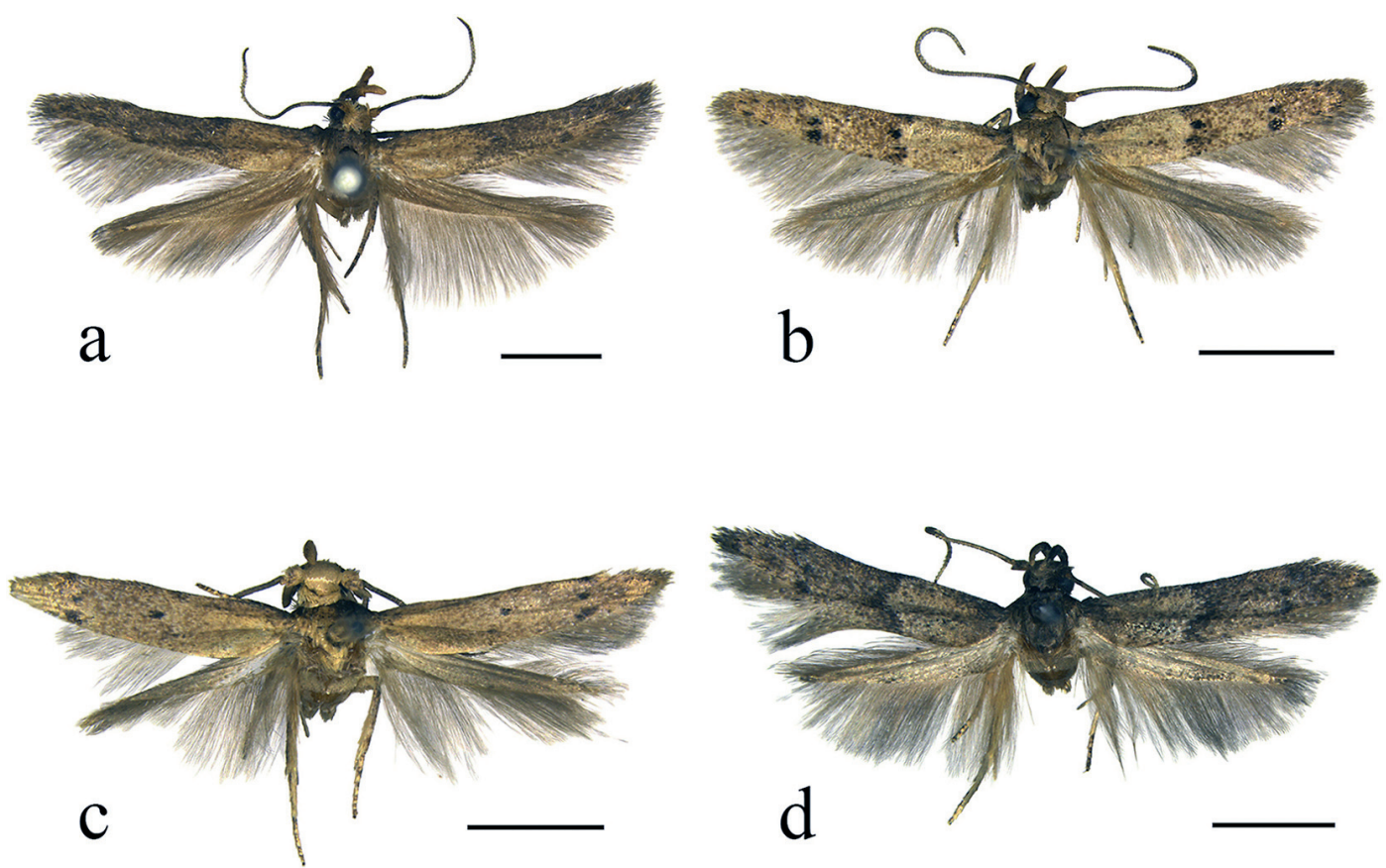

Fig. 5. Male adults of Lateantenna spp. - a. L. ianella. - b. L. lunata sp. n., holotype. - c. L. eurotella. - d. L. triangulata sp. n., holotype. Scale bars: $2.0 \mathrm{~mm}$.

broad, sub-trapezoid, sharply narrowed from distal $2 / 5$ to apex, forming a acutely-curved apical process, narrowly pointed apically; sacculus setose, narrow, almost uniform; basal spine-like projection arising from above sacculus, reaching distal $2 / 5$ of lower division of valva, slightly dilated in basal $1 / 4$. Juxta formed by two reniform plates, deeply emarginate anteriorly, almost membranous medially. Vinculum a narrow band. Phallus nearly as long as valva, curved ventrad, slightly broadened at base, narrowed to pointed apex; internal sclerite slightly curved ventrad; anellus setose to sub-apex.

Female genitalia (Fig. 8a). Apophyses posteriores approximately 3 times length of apophyses anteriores. Eighth tergum with a darkly pigmented longitudinal median streak, sternum with a darkly pigmented posterior spot medially (Fig. 8b). Intersegmental membrane posterior to seventh sternum with a sub-oval process arising from each side, posteriorly flanked by a sub-circular densely microtrichiate area. Seventh tergum straight along posterior margin, sternum broadly concave medially on posterior margin. Antrum small, cup-shaped. Ductus bursae approximately 3 times length of corpus bursae; internal wall with rows of microspinules ranging from inception of ductus seminalis toward corpus bursae, with overlapping platelets on anterior $1 / 3$ and becoming denser; ductus seminalis arising from ductus bursae proximal to ostium. Corpus bursae elliptical; signum a large dentate plate, with a hornshaped process (Fig. 8c), arising from middle of corpus bursae.

Distribution. China (Zhejiang).

Etymology. The specific epithet of this species is from the type locality.

\subsubsection{Lateantenna spiniharpella (Kuznetzov \&} Sinev, 1985) (Figs. 4b, 6b, 8d)

Neoblastobasis spiniharpella Kuznetzov \& Sinev, 1985: 535. Type locality: Russia.

Lateantenna spiniharpella (Kuznetzov \& Sinev): Sinev, 2014: 70.

Material examined. China: Tianjin: $61 \hat{\jmath}, 4$, Heishuihe, Mt. Baxian, 600 m, 4.VII.-12.IX. 2010, Yinghui Mou and Shurong Liu leg.; 4 $\overbrace{}^{\text {, }}$ 19 , Heishuihe, Mt. Baxian, 600 m, 18.VI.-1.VII. 2010, Mingrui Zhang and Shurong Liu leg.; 23 ${ }^{\lambda}$, 8 , , Heishuihe, Mt. Baxian, Ji County, 550 m, 
10.VI.-13.IX.2009, Bingbing Hu et al. leg.; 26 6옹 Heishuihe, Mt. Baxian, Ji County, $550 \mathrm{~m}$, 16.IX.2009, Zhipin Liang et al. leg.; 27ર̂, 4ㅇ, Heishuihe, Mt. Baxian, Ji County, 550 m, 19.VI.9.IX.2009, Jing Zhang et al. leg.; $7 \hat{\jmath}$, Mt. Baxian, 500 m, 8.-11.IX.2005, Houhun Li et al. leg.; 1 , Mt. Baxian, Ji County, 23.VII.2015, Houhun Li and Peixin Cong leg.; 1 9 , Mt. Pan, Ji County, 170 m, 21.VII.2004, Houhun Li et al. leg.

Diagnosis. Adult (Fig. 4b) forewing length 4.5-7.0 $\mathrm{mm}(n=173)$. Lateantenna spiniharpella is similar to L. brevicornis (Moriuti, 1987) and $L$. zhejiangensis $\mathbf{s p .} \mathbf{n}$. in the genital structures. It can be separated from $L$. brevicornis by the longer basal spine-like projection extending to the distal 1/6 of the lower division of the valva (Fig. $6 \mathrm{~b})$; the eighth sternum without a darkly pigmented posterior spot, and the corpus bursae being distinctly narrower than the posterior margin of the seventh segment (Fig. 8d). In L. brevicornis, the shorter basal spine-like projection extends to the distal 3/7 of the lower division of the valva (Fig. 6c); the eighth sternum has a darkly pigmented posterior spot medially, and the corpus bursae is nearly as wide as the posterior margin of the seventh segment (Fig. 9a). The differences between $L$. spiniharpella and L. zhejiangensis sp. n. are stated in the diagnosis of $L$. zhejiangensis sp. $\mathbf{n}$.

Host plants. Allium sativum L. (Amaryllidaceae) and Quercus serrata Thunberg (Fagaceae) (Moriuti 1987, Ohshima 2013).

Distribution. China (Taiwan, Tianjin), Korea, Japan, Russia.

\subsubsection{Lateantenna brevicornis (Moriuti, 1987)}

(Figs. 4c, 6c, 9a)

Neoblastobasis brevicornis Moriuti, 1987: 176. Type locality: Japan.

Lateantenna brevicornis (Moriuti): Sinev, 2014: 68.

Material examined. China: Zhejiang Province: 1ิ̄, Longtangshanzhuang, Qingliangfeng, Lin'an City, 500 m, 13.V.2017, Shuonan Qian and Ga-Eun Lee leg.; 1 , , Longtangshan Forestry Station, Qingliangfeng, Lin'an City, $550 \mathrm{~m}$, 14.V.2017, Shuonan Qian and Ga-Eun Lee leg.; $4 \hat{\jmath}$, Laofoyan Village, Shuangxikou Town,
Xianxialing, Jiangshan City, $400 \mathrm{~m}$, 27.29.V.2017, Shuonan Qian and Ga-Eun Lee leg.; 16今, 29, Mt. Gutian, Kaihua County, Quzhou City, 310 m, 17.-20.V.2017, Shuonan Qian and Ga-Eun Lee leg.; 1 $\hat{\jmath}$, Opium War Relics Park, Zhoushan City, 40 m, 31.V.2017, Shuonan Qian and Ga-Eun Lee leg.; 10^, 11q, Laoan, Mt. Tianmu, 555 m, 16.-19.VIII.2014, Aihui Yin, Qingyun Wang and Suran Li leg.; 6ภ, 1ㅇ, Sanmuping, Mt. Tianmu, 789 m, 10.-11.VIII. 2014, Aihui Yin, Qingyun Wang and Suran Li leg.; 3今, 2 ㅇ, Qianjiangyuan, Mt. Tianmu, $866 \mathrm{~m}$, 12.-15.VIII.2014, Aihui Yin, Qingyun Wang and Suran Li leg.; 1 $\jmath^{\lambda}$, Tianmushan Administration, 335 m, 19.VII. 2015, Aihui Yin, Kang Lou and Tao Wang leg.; 4^, $3 \circ$, Qingliangfeng, Lin'an City, 900 m, 8.-12.VIII.2005, Yunli Xiao leg.; 2ิ, Shunxiwu, Qingliangfeng, $390 \mathrm{~m}, 18 .-$ 20.V.2012, Linlin Yang and Zhenguo Zhang leg.; 2ð, Mt. Longtang, Qingliangfeng, $500 \mathrm{~m}$, 22.V.2012, Linlin Yang and Zhenguo Zhang leg.; $5 \widehat{\jmath}, 5$, , Yulingguan, Qingliangfeng, 220 m, 23.24.VII.2014, Aihui Yin, Xuemei $\mathrm{Hu}$ and Qingyun Wang leg.; 13ð̂, 10 , Jiufu Village, Mt. Longtang, 520 m, 25.-26.VII.2014, Aihui Yin, Xuemei Hu and Qingyun Wang leg.; 8今̂, Jiufu Village, Mt. Longtang, $520 \mathrm{~m}, 2$ 27.-31.VIII.2014, Aihui Yin, Qingyun Wang and Suran Li leg.; $2 \widehat{\jmath}$, Huangtan Forestry Farm, Renchuan Town, Jinhua City, 909 m, 30.VII.2015, Aihui Yin,

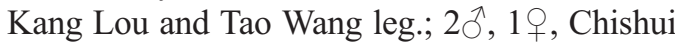
Village, Zhangshui Town, Yinzhou District, Ningbo City, 450 m, 26.VII.2015, Aihui Yin, Kang Lou and Tao Wang leg.; $1 \partial^{\lambda}$, Mt. Jiulong, $400 \mathrm{~m}, 6$. VIII.2011, Linlin Yang and $\mathrm{Na}$ Chen leg.; 10̂, Longxushan Village, Mt. Longxu, 778 m, 21.VIII.2014, Aihui Yin, Qingyun Wang and Suran Li leg.; 1ð̄, 2ᄋ, Pinggang, Mt. Longxu, 754 m, 24.-26.VIII.2014, Aihui Yin, Qingyun Wang and Suran Li leg.; 1ð, 5 9 , Shimendong, Qingtian Town, $102 \mathrm{~m}$, 19.-21.VIII.2016, Qingyun Wang, Meiqing Yang and Ping Liu leg.; Yunnan Province: 1 $\hat{0}$, Ruili Botanical Garden, 1,000 m, 8.VIII.2005, Yingdang Ren leg.; $1 \overbrace{}^{\Uparrow}$, 19, Nankang Administration, Baoshan City, 2,009 m, 16.-20.VII.2015, Kaijian Teng and Xia Bai leg.; 1ð̂, Gaoligong Mountain National Forest Park, Baoshan City, 2,157 m, 24.VII.2015,

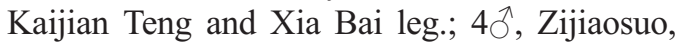
Jingdong County, 1,140 m, 4.-9.VI.2013, 

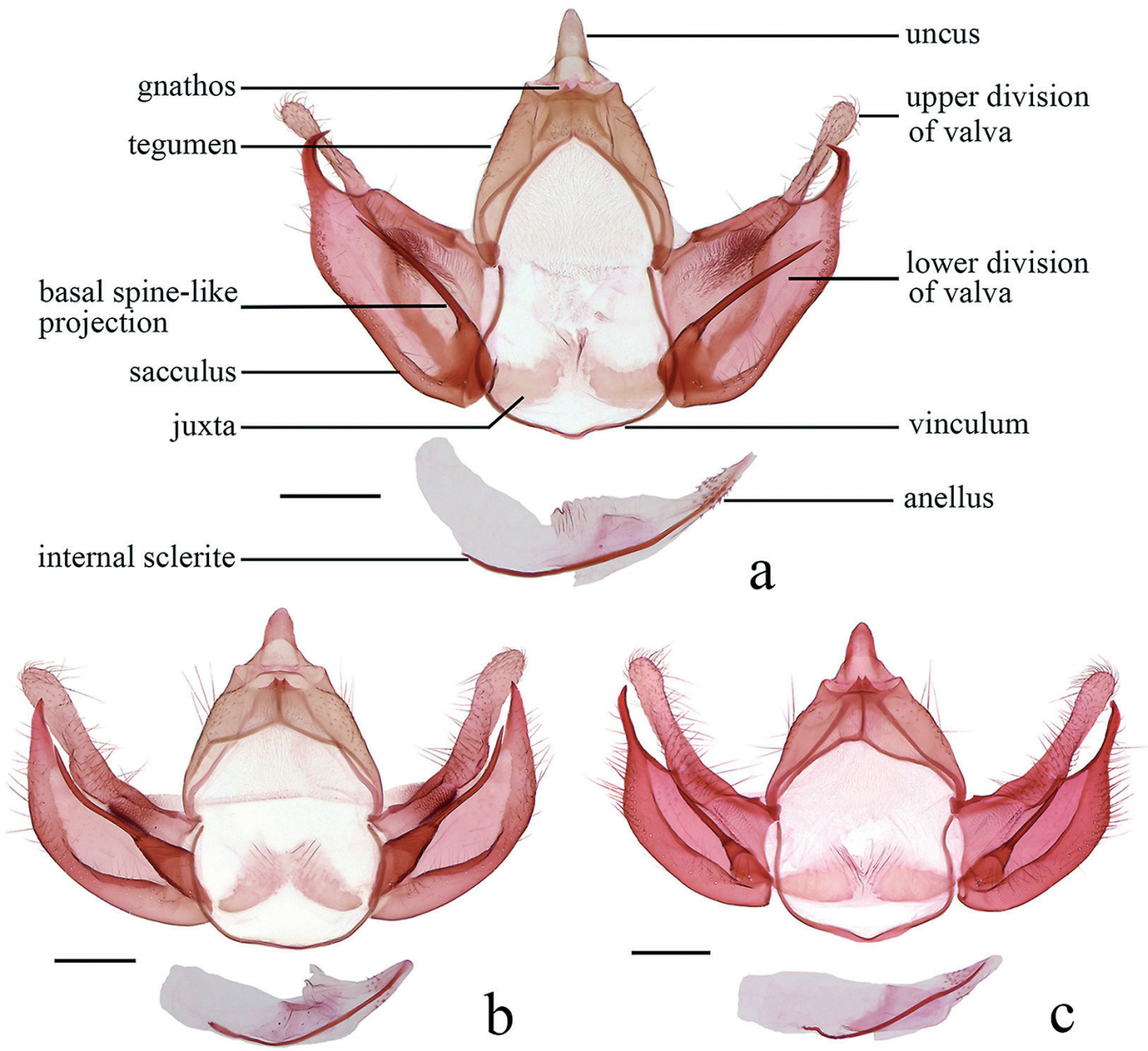

$\mathrm{b}$

c
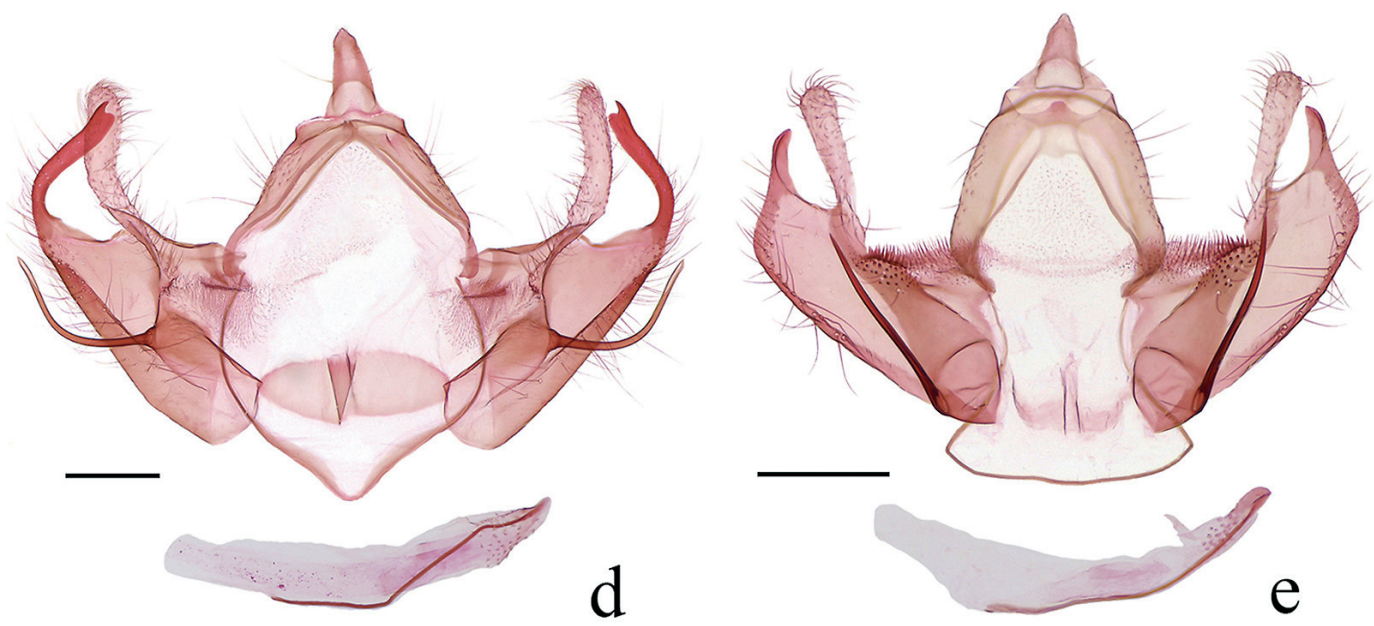

Fig. 6. Male genitalia of Lateantenna spp. - a. L. zhejiangensis sp. n., holotype, slide No. TKJ17212. - b. L. spiniharpella, slide No. TKJ17117. - c. L. brevicornis, slide No. TKJ17261. - d. L. decolor, slide No. TKJ17189. - e. L. semicircularis sp. n., paratype, slide No. TKJ17215. Scale bars: $0.2 \mathrm{~mm}$. 
Zhenguo Zhang leg.; $1 \lesssim, 1$, Taiyanghe National Forest Park, Puer City, 1,626 m, 8.VII.2013, Shurong Liu, Yuqi Wang and Kaijian Teng leg.; Tibet Autonomous Region: 1§̂, Beibeng Town, Motuo County, 987 m, 12.VIII.2017, Mujie Qi and Xiaofei Yang leg.; 1ð̃, Beibeng Town, Motuo County, 810 m, 13.VIII.2017, Mujie Qi and Xiaofei Yang leg.

Diagnosis. Adult (Fig. 4c) forewing length $5.0-7.0 \mathrm{~mm}(n=139)$. Lateantenna brevicornis is similar to L. spiniharpella (Kuznetzov \& Sinev, 1985) and L. zhejiangensis sp. n. The differences between them can be found above.

Distribution. China (Taiwan, Tibet, Yunnan, Zhejiang), Japan, Russia.

\subsubsection{Lateantenna decolor (Meyrick, 1907)}

(Figs. 4d, 6d, 9b)

Blastobasis decolor Meyrick, 1907: 150. Type locality: Sri Lanka.

Neoblastobasis decolor (Meyrick): Kuznetzov \& Sinev, 1985: 536.

Lateantenna decolor (Meyrick): Sinev, 2014: 69.

Material examined. China: Tianjin: 1ふ, Heishuihe, Mt. Baxian, 600 m, 12.IX.2010, Yinghui Mou and Shurong Liu leg.; 1 $\varrho^{\lambda}, 2$, Limutai, Ji County, 300 m, 1.VII.2007, Houhun

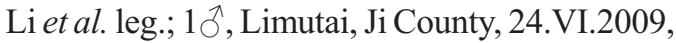
Bingbing Hu et al. leg.; 19, Limutai, Ji County, 25.VI.2009, Zhipin Liang et al. leg.; 3 , Limutai, Ji County, 300 m, 11.VI.2004, Houhun Li et al. leg.; 6^, Mt. Jiulong, Ji County, 150 m, 5.7.IX.2001, Houhun Li leg.; 1ð̂, Mt. Jiulong, Ji County, 130 m, 9.VI.2004, Houhun Li et al. leg.; $1{ }^{\lambda}, 19$, Mt. Jiulong, Ji County, $180 \mathrm{~m}$, 10.VI.2004, Houhun Li et al. leg.

Diagnosis. Adult (Fig. 4d) forewing length $5.0-7.5 \mathrm{~mm}(n=18)$. Lateantenna decolor is similar to L. moffetti (Adamski \& Brown, 2002) in the male genitalia, but it can be separated from the latter by the intact juxta (Fig. 6d), while in $L$. moffetti the juxta is divided into two parts. Lateantenna decolor is also similar to $L$. spiniharpella (Kuznetzov \& Sinev, 1985) in the female genitalia, but it can be separated from the latter by the intersegmental membrane posterior to seventh segment bearing a narrowly clubbed process extending from each side (Fig. 9b), while this process is sub-oval in L. spiniharpella (Fig. 8d).

Host plants. Tamarindus indicus L. (Fabaceae) and Ficus racemosa L. (Moraceae) (Moriuti 1987). Citrus unshiu Marc. (Rutaceae) and Diospyros kaki Thunberg (Ebenaceae) (Ohshima et al. 2018).

Distribution. China (Taiwan, Tianjin), Azerbaijan, Georgia, India, Japan, Korea, Russia, Sri Lanka.

\subsubsection{Lateantenna semicircularis Teng \& Wang, sp. n. (Figs. 4e, 6e, 9c)}

Type material. China: Zhejiang Province: Holotype: ${ }^{\top}$, Sanmuping $\left(30.37^{\circ} \mathrm{N}, 119.43^{\circ} \mathrm{E}\right)$, Mt. Tianmu, 789 m, 11.VIII.2014, Aihui Yin, Qingyun Wang and Suran Li leg., slide No. TKJ16093. Paratypes: 1 , same data as holotype; 1今, Zhonglieci, Mt. Tianmu, $400 \mathrm{~m}$, 1.VIII.2011, Linlin Yang and $\mathrm{Na}$ Chen leg.; $1{ }^{\widehat{O}}$, 2 , , Longxushan Village, Mt. Longxu, $778 \mathrm{~m}$, 20.-21.VIII.2014, Aihui Yin, Qingyun Wang and Suran Li leg.; $2 \hat{\jmath}, 1$ ㅇ, Xiguan, Mt. Tianmu, 566 m, 18.-19.VII.2014, Aihui Yin, Xuemei Hu and

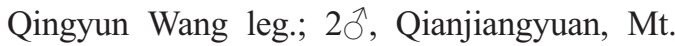
Tianmu, $866 \mathrm{~m}, 12 .-15$. VIII.2014, Aihui Yin, Qingyun Wang and Suran Li leg.

Diagnosis. Lateantenna semicircularis sp. $\mathbf{n}$. is characterized in the male genitalia by the gnathos being convex semicircularly at middle and lacking dentitions on the posterior margin. It is similar to L. zhejiangensis sp. n. in the male genitalia by having a heavily sclerotized ventral band along the ventral margin of the upper division of the valva. It can be separated from the latter by the gnathos lacking dentitions on the posterior margin, while the gnathos has two small dentitions medially on the posterior margin in $L$. zhejiangensis sp. $\mathbf{n}$.

Description. Adult (Fig. 4e) forewing length 4.3-5.5 $\mathrm{mm}(n=11)$. Head pale greyish brown, scales tipped with pale yellow. Antenna with scape greyish brown, scales tipped with greyish white on dorsal surface, pale yellow on ventral surface; pecten brown; flagellum brown, ciliated on ventral surface in male, first flagellomere dilated, forming a notch in male. Labial palpus with outer surface dark brown, mixed with scales tipped with pale yellow, inner surface pale yel- 


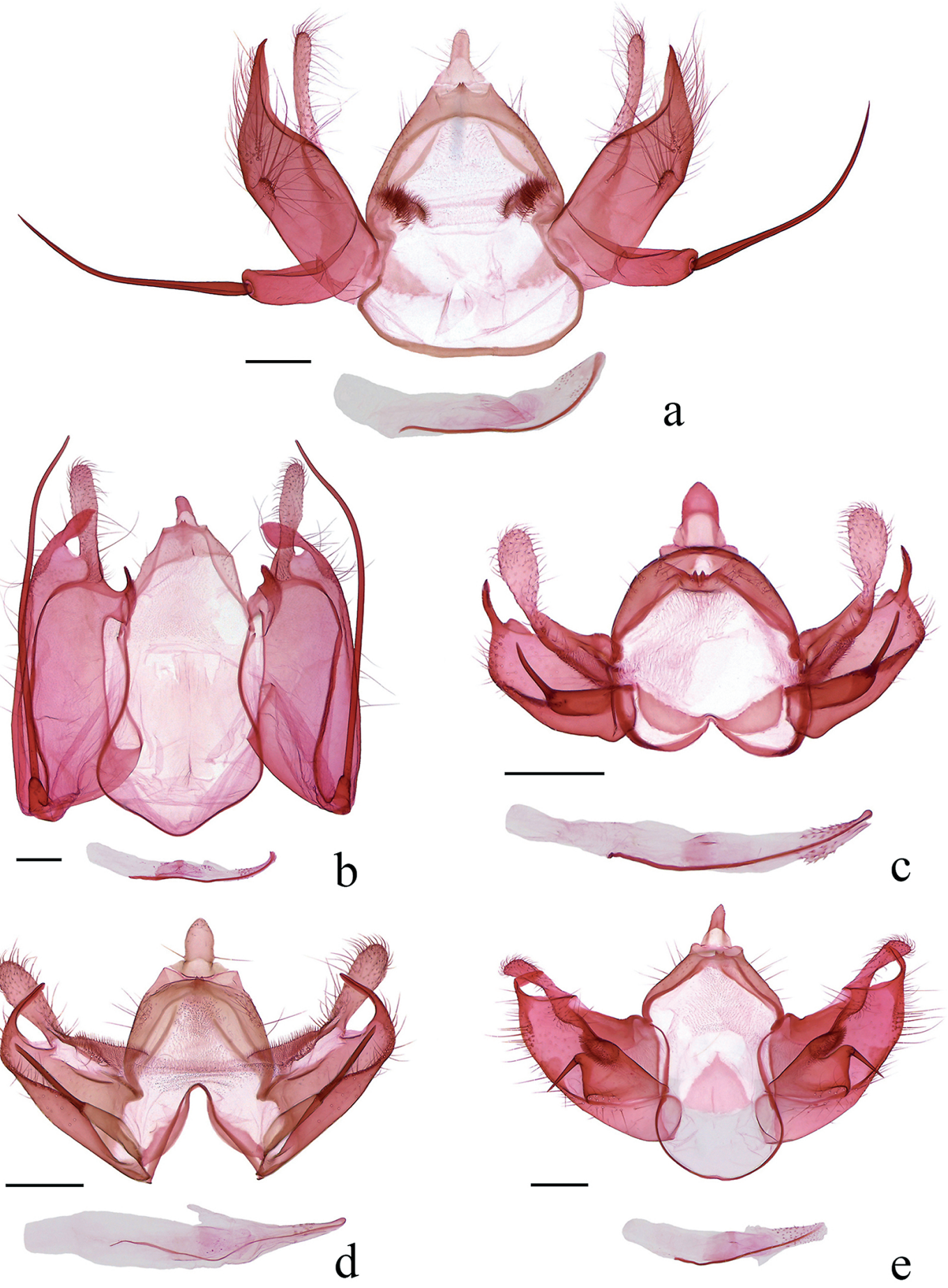

Fig. 7. Male genitalia of Lateantenna spp. - a. L. camelliae, slide No. TKJ17170. - b. L. ianella, slide No. TKJ17266. - c. L. lunata sp. n., paratype, slide No. TKJ17254. - d. L. eurotella, slide No. TKJ17311. - e. L. triangulata sp. n., paratype, slide No. TKJ17259. Scale bars: $0.2 \mathrm{~mm}$. 


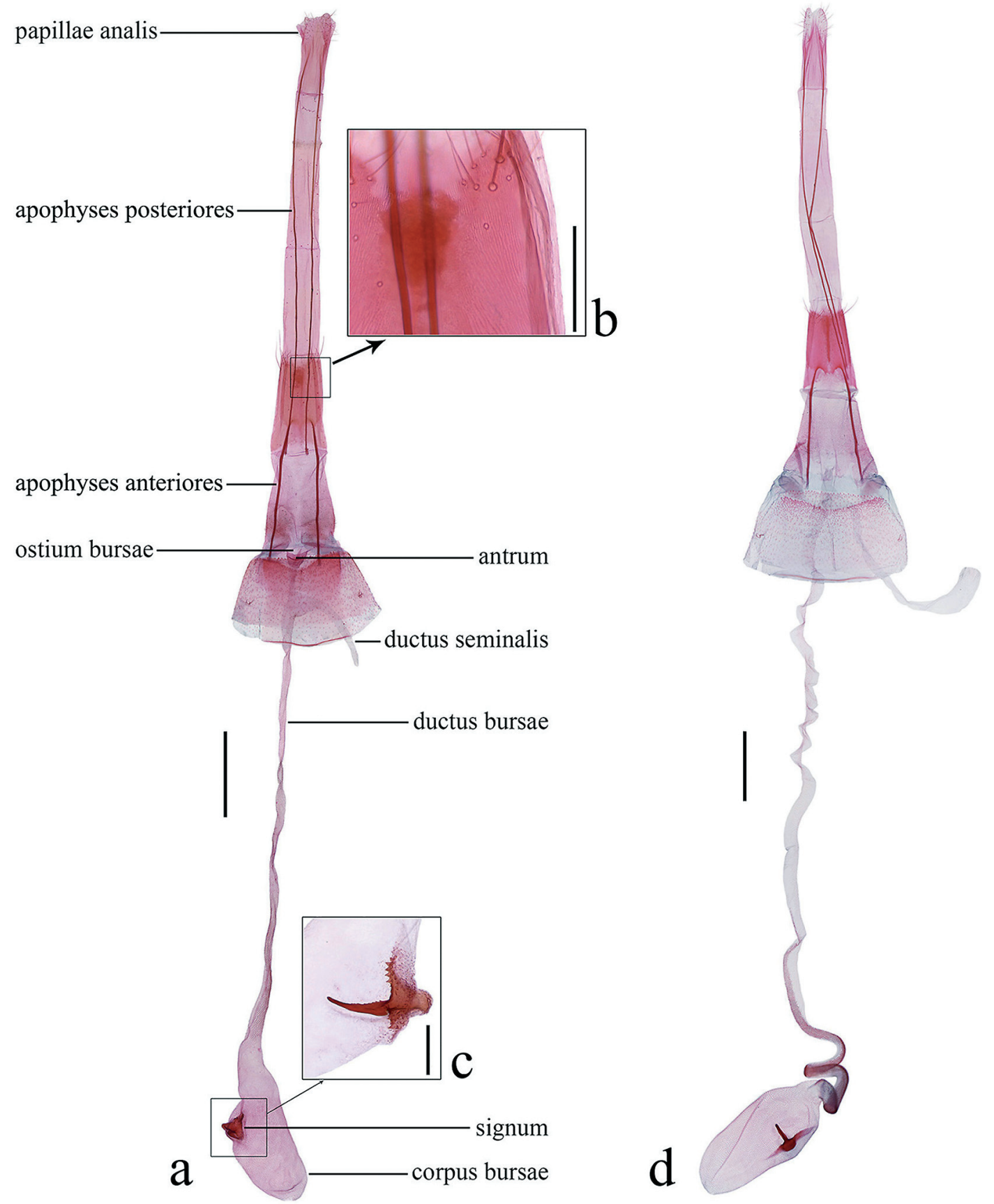

Fig. 8. Female genitalia of Lateantenna spp. - a-c. L. zhejiangensis sp. n., paratype, slide No. TKJ17413. - b. enlarged darkly pigmented posterior spot on eighth sternum, slide No. TKJ17201. - c. enlarged signum, slide No. TKJ17199. - d. L. spiniharpella, slide No. TKJ17057. Scale bars: 0.5 mm (a, d), 0.1 mm (b, c).

low; third segment slightly shorter than second, pointed apically, outer surface paler than that of second segment in male; labial palpus in female distinctly narrower than in male. Haustellum pale grey. Mesonotum and tegula dark brown, scales tipped with greyish yellow. Forewing brown, scales tipped with greyish white; dark brown basally, paler to basal $2 / 5$, distal $3 / 5$ with dark 
brown scales; discocellular and tornal spots black; submedian fascia dark brown, its outer margin obscure, inner margin edged with pale grey scales tipped with greyish white; fringe pale greyish brown, intermixed with dark brown and greyish brown scales tipped with greyish white. Hindwing and fringe pale greyish brown, becoming darker from base to apex. Legs dark brown and with brown scales tipped with greyish white on ventral surface, greyish white on dorsal surface and on tarsomeres apically.

Male genitalia (Fig. 6e). Uncus slightly curved ventrad, sparsely setose, broad at base, narrowed to narrowly rounded apex. Gnathos sub-quadrate, semicircularly convex medially on posterior margin. Upper division of valva wide at base, narrowed triangularly to middle; basal half with dense microtrichiae on costal area, heavily sclerotized and forming a wedge shaped band ventrally, ventral band with dense granules and spines in its distal 2/5; distal half clavate and setose. Lower division of valva with basal $3 / 4$ parallel-sided, sharply narrowed from distal 1/4 to apex, forming a foliate, inwardly curved apical process with rounded apex; sacculus narrow, setose along distal $2 / 3$; basal spine-like projection arising from above sacculus, about $2 / 3$ length of lower division of valva, spherically dilated basally. Juxta a transverse band, convex sub-triangularly at middle on posterior margin. Vinculum a thin band. Phallus nearly as long as valva, curved ventrad, slightly broad at base, gradually narrowed to basal 3/4, distal 1/4 almost uniform except rounded apically; internal sclerite slightly curved ventrad, slightly dilated distally; anellus bearing dense cone-like setae sub-apically.

Female genitalia (Fig. 9c). Apophyses posteriores approximately 3 times length of apophyses anteriores. Eighth tergum with a darkly pigmented longitudinal median streak. Intersegmental membrane posterior to seventh sternum with a sub-oval process on each side. Seventh tergum straight on posterior margin, sternum broadly concave medially on posterior margin. Ductus bursae approximately 2.5 times length of corpus bursae, internal wall with overlapping platelets on anterior $2 / 5$; ductus seminalis arising from ductus bursae proximal to ostium. Corpus bursae oval; signum a small spine, at anterior $1 / 4$ of corpus bursae.
Distribution. China (Zhejiang).

Etymology. The specific epithet of this species is derived from the Latin semicircularis (semicircular), in reference to the gnathos being semicircularly convex medially on the posterior margin.

\subsubsection{Lateantenna camelliae (Chen \& Wu, 2013) (Figs. 4f, 7a, 10a)}

Neoblastobasis camelliae Chen \& Wu, 2013: 557. Type locality: China (Jiangxi).

Lateantenna camelliae (Chen \& Wu): Sinev, 2014: 68.

Material examined. China: Tianjin: $1 \hat{\jmath}, 1 \propto$, Mt. Pan, Ji County, 170 m, 21.VII.2004, Houhun Li et al. leg.; 1ठ, 19, Mt. Jiulong, Ji County, 200 m, 28.VI.2004, Houhun Li et al. leg.

Diagnosis. Adult (Fig. 4f) forewing length $5.5-6.0 \mathrm{~mm}(n=4)$. Lateantenna camelliae is similar to L. ianella (Adamski, 2003) in the male genitalia, but it can be separated from the latter by the lower division of the valva produced to a triangular apical process and the phallus nearly as long as the valva (Fig. 7a). In L. ianella, the apical process of the lower division of the valva is dilated sub-apically and the phallus is shorter than the valva (Fig. $7 b$ ).

Description. Female genitalia (Fig. 10a). Apophyses posteriores approximately 2.5 times length of apophyses anteriores. Eighth tergum without a darkly pigmented longitudinal median streak. Intersegmental membrane posterior to seventh segment with an elongate area of dense microtrichiae flanking ostium, anterior $2 / 5$ heavily sclerotized on dorsal surface. Seventh sternum nearly straight on posterior margin, tergum with 3-4 transverse, irregular rows of spine-like setae. Ductus bursae approximately 3 times length of corpus bursae, internal wall with rows of microspinules ranging from inception of ductus seminalis toward corpus bursae, with overlapping platelets on anterior $1 / 3$ becoming denser gradually; ductus seminalis arising from ductus bursae proximal to ostium. Corpus bursae oval, with dense granules; signum arising from near posterior $1 / 3$ of corpus bursae, horn-shaped, with a sclerotized crescent-shaped basal plate bearing many small dentitions. 

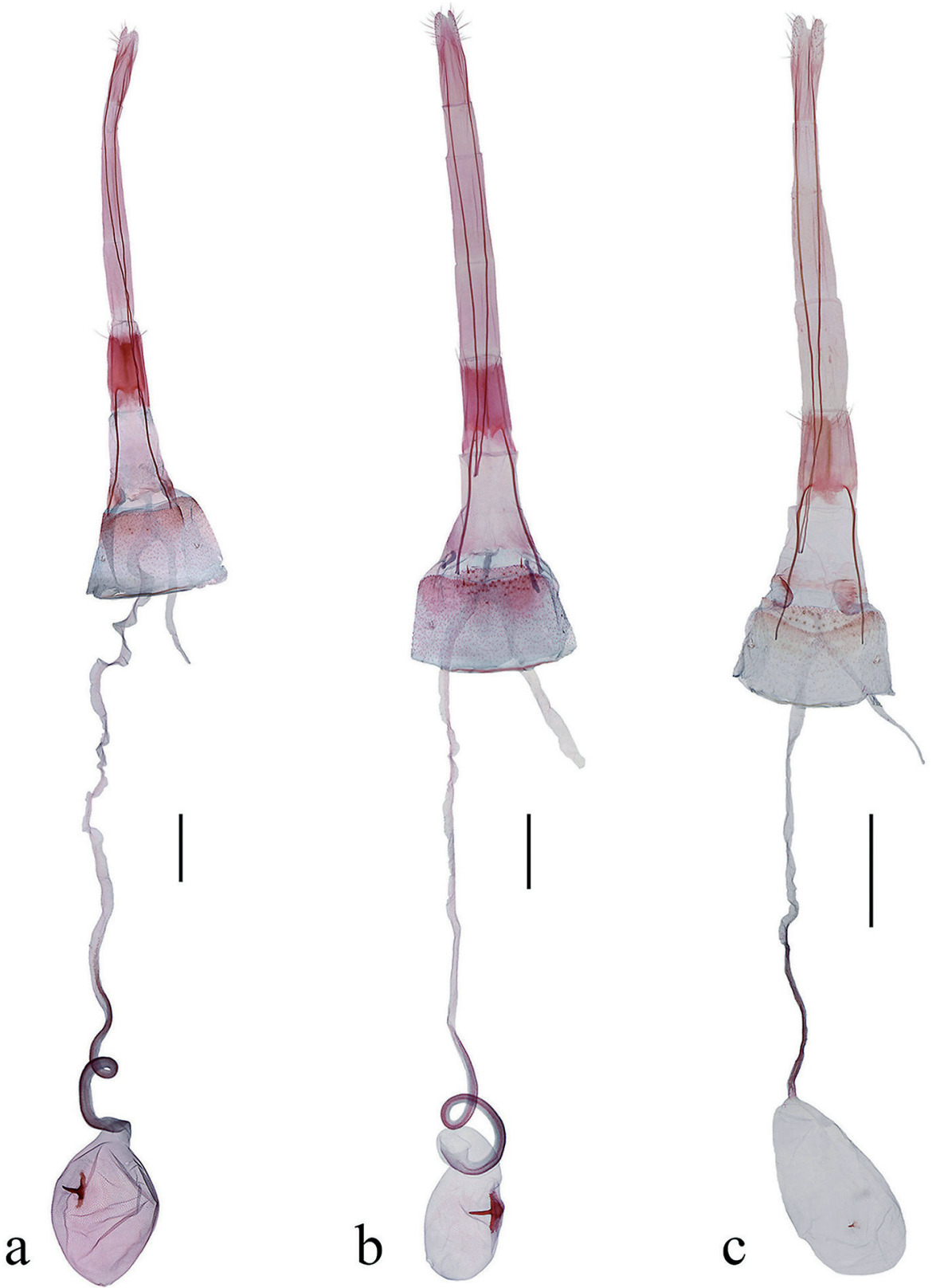

Fig. 9. Female genitalia of Lateantenna spp. - a. L. brevicornis, slide No. TKJ17125. - b. L. decolor, slide No. TKJ17085. - c. L. semicircularis sp. n., paratype, slide No. TKJ17245. Scale bars: $0.5 \mathrm{~mm}$.

Host plant. Camellia oleifera Abel (Theaceae) (Chen et al. 2013).

Distribution. China (Jiangxi, Tianjin), Korea.

Note. The female of L. camelliae is described for the first time.
3.2.7. Lateantenna ianella (Adamski, 2003)

(Figs. 5a, 7b, 10b)

Blastobasis ianella Adamski, 2003: 5. Type locality: Thailand.

Neoblastobasis ianella (Adamski): Chen et al., 2013: 557. 

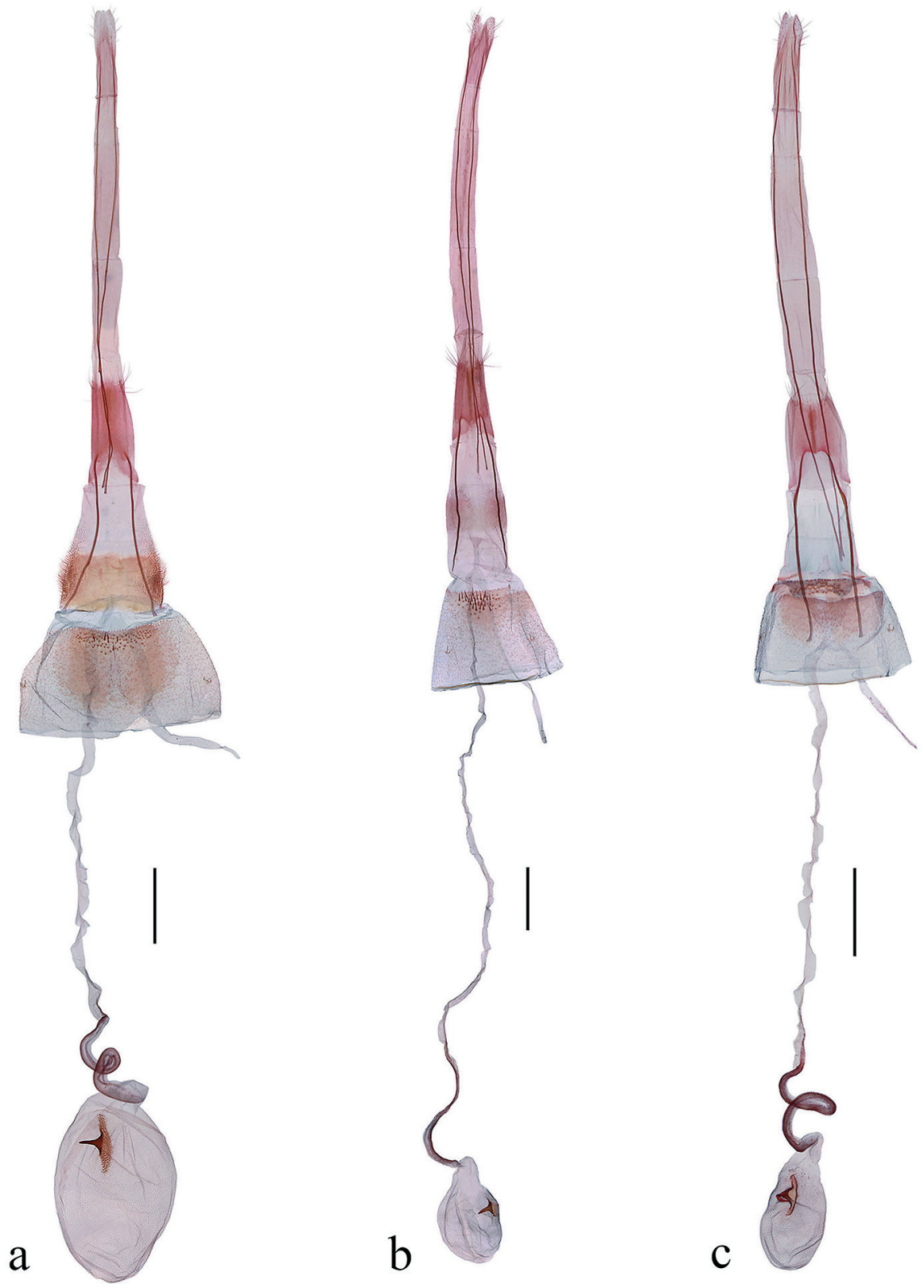

Fig. 10. Female genitalia of Lateantenna spp. - a. L. camelliae, slide No. TKJ17177.

- b. L. ianella, slide No. TKJ17279. - c. L. eurotella, slide No. TKJ17312. Scale bars: $0.5 \mathrm{~mm}$.

\section{Lateantenna ianella (Adamski): Sinev, 2014: 69.}

Material examined. China: Yunnan Province: $5 \hat{\jmath}, 4$, Taiyanghe Nature Reserves, Puer City, 1,600 m, 11.VII.2013, Zhenguo Zhang leg.; 6 ${ }^{\lambda}$, 9 ㅇ, Taiyanghe Nature Reserves, $1,450 \mathrm{~m}, 22$.V.2.IX.2014, Zhenguo Zhang leg.; 2へ, 1,
Taiyanghe National Forest Park, Puer City, 1,626 m, 8.VII.2013, Shurong Liu, Yuqi Wang and Kaijian Teng leg.; 1 , , Taiyanghe National Forest Park, Puer City, 1,450 m, 4.IV.2015, Kaijian Teng leg.; $1{ }^{\top}, 1$, , Yexianggu, Xishuangbanna, $762 \mathrm{~m}$, 18.-20.VII.2014, Kaijian Teng et al. leg.; 1ð, 1 ㅇ, Yexianggu, Xishuangbanna, $762 \mathrm{~m}, 8 .-12$. 
VII.2015, Kaijian Teng and Xia Bai leg.

Diagnosis. Adult (Fig. 5a) forewing length $6.0-7.0 \mathrm{~mm}(n=32)$. Lateantenna ianella is characterized by the basal spine-like projection longer than the valva and the apical process of the lower division of the valva dilated sub-apically. It is similar to L. camelliae (Chen \& Wu, 2013) in the male genitalia, and the differences between them are stated under L. camelliae.

Description. Female genitalia (Fig. 10b). Apophyses posteriores approximately 3 times length of apophyses anteriores. Eighth tergum with a darkly pigmented longitudinal median streak. Ostium bursae at anterior $1 / 3$ of membrane between seventh and eighth segments, anterior to two ventro-lateral, sub-circular, highly microtrichiate areas. Seventh sternum with posterior margin nearly straight, tergum with 3-4 transverse, irregular rows of spine-like setae. Antrum elongate funnel-shaped. Ductus bursae approximately 7 times length of corpus bursae, internal wall with rows of microspinules ranging from inception of ductus seminalis toward corpus bursae, with overlapping platelets on anterior $1 / 3$ becoming denser gradually; ductus seminalis arising from ductus bursae proximal to ostium. Corpus bursae oval, with dense granules; signum arising from near middle of corpus bursae, hornshaped, with a sclerotized sub-triangular basal plate bearing many small dentitions.

Distribution. China (Yunnan), Thailand.

Notes. This species is newly recorded for China, and its female is described for the first time.

\subsubsection{Lateantenna lunata Teng \& Wang, sp. n.} (Figs. 5b, 7c)

Type material. China: Yunnan Province: Holotype: §, Wufenchang $\left(21.72^{\circ} \mathrm{N}, 100.15^{\circ} \mathrm{E}\right)$, Daluo Town, Menghai County, Jinghong City, 640 m, 2.VIII.2016, Kaijian Teng, Ga-Eun Lee and Tao Wang leg., slide No. TKJ17353. Paratypes: $7 \hat{\jmath}$, same data as holotype; $3 \hat{\jmath}$, Yexianggu, Xishuangbanna, 762 m, 8.-10.VII.2015, Kaijian Teng and Xia Bai leg.; 1§, Bakaxiaozhai, Menglun Town, Mengla County, Xishuangbanna, $620 \mathrm{~m}$, 6.VIII.2010, Yinghui Sun and Lixia Li leg.; 1 $\lesssim$, Tropical Botanical Garden, Menlun Town, 570 m, 15.VIII.2005, Yingdang
Ren leg.; 1ठ, Mengyuan Village, Mengla County, Xishuangbanna, 640 m, 10.VIII.2010, Yinghui Sun and Lixia Li leg.; $1{ }^{\lambda}$, Bubang Village, Mengla County, 650 m, 23.VIII.2005, Yingdang Ren leg.; $1 \hat{\jmath}$, Guanping, Mengyang Town, 1,200 m, 20.VIII.2005, Yingdang Ren leg.; $2 \hat{\jmath}$, Taiyanghe National Forest Park, Puer City, 1,626 m, 6.-7.VII.2013, Shurong Liu, Yuqi Wang and Kaijian Teng leg.; $1 \lesssim$, Taiyanghe Nature Reserves, Puer City, 1,450 m, 12.VIII.2016, Kaijian Teng, Ga-Eun Lee and Tao Wang leg.; 4ก. Pingbian County, Honghe, 1,700 m, 5.XI.2010, Bingbing Hu, Jing Zhang and Yanpeng Cai leg.; Hainan Province: 2ર, Yongxing Island, 19.VI.2017, Bo Cai et al. leg.

Diagnosis. Lateantenna lunata $\mathbf{s p .} \mathbf{n}$. is similar to L. eurotella (Adamski, 2010) in the male genitalia, but it can be separated from the latter by the lower division of the valva with a triangular dorso-apical process, and the juxta extremely constricted medially and lunate laterally (Fig. 7c). In L. eurotella, the lower division of the valva lacks a dorso-apical process, and the juxta is uniformly narrow in the median 1/3 (Fig. 7d).

Description. Adult (Fig. 5b) forewing length $3.5-5.5 \mathrm{~mm}(n=25)$. Head pale greyish brown, scales tipped with pale yellow on vertex and along margin of eye, pale yellow on frons. Antenna with scape pale yellow, intermixed with brown scales on dorsal surface, greyish white on ventral surface; pecten pale yellowish brown; flagellum dark brown, ciliated on ventral surface, first flagellomere pale yellow, dilated, forming a notch. Labial palpus with outer surface dark brown, mixed with scales tipped with greyish white, inner surface pale yellow, second segment greyish white apically; third segment nearly as long as second, blunt at apex. Haustellum pale grey. Mesonotum and tegula brown, scales tipped with pale yellow, intermixed with pale greyish brown scales tipped with pale yellow. Forewing yellowish brown, basal $1 / 3$ with pale greyish brown scales tipped with pale yellow, distal $2 / 3$ with pale brown or brown scales tipped with greyish white; humeral patch brown, with scales tipped with pale yellow; discal, discocellular, tornal and marginal spots black; submedian fascia dark brown, complete or interrupted medially, slightly arched outwardly near middle; fringe greyish brown, intermixed with pale greyish 
brown scales tipped with greyish white. Hindwing and fringe greyish brown, yellowish brown from vein $\mathrm{CuP}$ to dorsum. Legs dark brown and with brown scales tipped with greyish white on ventral surface, greyish white on dorsal surface, all tarsomeres greyish white apically.

Male genitalia (Fig. 7c). Uncus slightly curved ventrad, sparsely setose, broad at base, slightly narrowed to middle, parallel-sided from middle to distal $1 / 4$, distal $1 / 4$ nearly triangular, slightly narrowed to narrowly rounded apex. Gnathos rectangular, with two small dentitions medially on posterior margin. Valva with upper division broad at base, slightly narrowed to middle, then dilated and forming an ovate setose distal part, microtrichiate on basal $1 / 4$ along ventral margin. Lower division of valva broad, sub-rectangular; apex obliquely straight, with a triangular dorso-apical process, with a spine-like apical process curved inward; sacculus broad at base, narrowed to apex; basal spine-like projection extending to sub-apex of lower division of valva, dilated from base to $1 / 2$. Juxta extremely constricted medially, large lunate laterally. Vinculum a narrow band, extending backward medially, weakly fused with juxta at middle. Phallus slightly longer than valva, curved ventrad, basal half almost uniform, distal half gradually narrowed to rounded apex; internal sclerite slightly curved ventrad; anellus bearing dense cone-like setae.

Female unknown.

Distribution. China (Hainan, Yunnan).

Etymology. The specific epithet of this species is derived from the Latin lunatus (lunate), in reference to the laterally lunate juxta.

\subsubsection{Lateantenna eurotella (Adamski, 2010)}

(Figs. 5c, 7d, 10c)

Neoblastobasis eurotella Adamski, 2010: 526.

Type locality: United Arab Emirates.

Neoblastobasis songi Park, In Park et al. 2014: 234.

Lateantenna songi (Park): Park \& Adamski, 2017: 1132.

Lateantenna eurotella (Adamski): Sinev, 2014: 69.
Material examined. China: Yunnan Province: $1 \hat{0}, 1$, , Taiyanghe National Forest Park, Puer City, 1,626 m, 6.-8.VII.2013, Shurong Liu, Yuqi Wang and Kaijian Teng leg.

Diagnosis. Adult (Fig. 5c) forewing length $4.5-6.5 \mathrm{~mm}(n=2)$. Lateantenna eurotella is similar to L. lunata sp. $\mathbf{n}$. in the male genitalia, and the differences between them are stated under $L$. lunata sp. n. Lateantenna eurotella is also similar to L. spiniharpella (Kuznetzov \& Sinev, 1985) in the female genitalia, but it can be separated from the latter by the large bowl-shaped antrum (Fig. 10c), which is absent in L. spiniharpella (Fig. 8d).

Distribution. China (Yunnan), Korea, United Arab Emirates.

Note. This species is recorded for the first time in China.

\subsubsection{Lateantenna triangulata Teng \& Wang,} sp. n. (Figs. 5d, 7e)

Type material. China: Yunnan Province: Holotype: $\delta$, Taiyanghe National Forest Park $\left(22.68^{\circ} \mathrm{N}, 101.03^{\circ} \mathrm{E}\right)$, Puer City, $1,450 \mathrm{~m}$, 4.VII.2015, Kaijian Teng leg., slide No. TKJ17287. Paratypes: 13 $\hat{\jmath}$, Taiyanghe Nature Reserves, 1,450 m, 22.V.-2.IX.2014, Zhenguo Zhang leg.; $2 \AA$, Taiyanghe Nature Reserves, Puer City, 1,600 m, 11.VII.2013, Zhenguo Zhang leg.; 1亏ิ, Ruili Botanical Garden, 1,000 m, 7.VIII.2005, Yingdang Ren leg.

Diagnosis. Lateantenna triangulata sp. n. can be separated from its congeners by the basal half of the basal spine-like projection dilated subrectangularly, and by having a large triangular juxta in the male genitalia.

Description. Adult (Fig. 5d) forewing length 4.7-6.0 mm $(n=17)$. Head greyish brown, scales tipped with greyish white. Antenna with scape brown or greyish brown, scales tipped with greyish white on dorsal surface, pale yellow on ventral surface; pecten pale brown; flagellum brown, ciliated on ventral surface in male, first flagellomere dilated, forming a notch in male. Labial palpus dark brown, mixed with scales tipped with greyish white, second segment with pale greyish brown or greyish white scales along dorsal margin in distal half on inner surface; third segment nearly as long as second, pale greyish brown except greyish white apically, and with a pale grey 
band along dorsal margin on inner surface, distal $1 / 3$ gradually narrowed to blunt apex. Haustellum pale grey. Mesonotum and tegula brown. Forewing brown, scales tipped with greyish white; dark brown at base, becoming paler to basal $2 / 5$, with dark brown scales on distal 3/5; discocellular and tornal spots rounded and black; submedian fascia dark brown, inner margin edged with pale grey scales tipped with greyish white, sub-triangularly curved outward near middle; fringe pale greyish brown, intermixed with brown scales tipped with greyish white. Hindwing and fringe pale greyish brown, darkening from base to apex. Legs dark brown and with brown scales tipped with greyish white on ventral surface, greyish white on dorsal surface; tibiae of mid- and hindlegs as well as each tarsomere of all tarsi greyish white apically.

Male genitalia (Fig. 7e). Uncus slightly curved ventrad, sparsely setose, broad at base, narrowed to basal $1 / 3$, parallel-sided medially, distal $1 / 3$ slightly narrowed to rounded apex. Gnathos rectangular, weakly sclerotized, with two small dentitions at middle on posterior margin. Valva with upper division broad at base, slightly narrowed to middle, basal half with microtrichiae, distal half clavate and setose, slightly constricted at distal $1 / 4$, broadly rounded apically; ventral margin with dense spine-like setae before middle. Lower division of valva with basal $3 / 5$ broad, sharply narrowed from distal $2 / 5$ to apex, forming a narrowly elongate foliate apical process curved inward; sacculus broad at base, slightly narrowed to middle, equally narrow in distal half; basal spine-like projection arising from above sacculus, its basal half largely dilated sub-rectangularly, distal half bearing a spine arising from dorso-apical corner directing obliquely ventrad, extending beyond ventral margin. Juxta large, triangular. Vinculum a narrow band. Phallus shorter than valva, curved ventrad, almost uniform from base to basal $1 / 3$, gradually narrowed medially, almost uniform from distal $1 / 3$ to apex; internal sclerite slightly curved ventrad at basal 1/6; anellus bearing dense cone-like setae.

Female unknown.

Distribution. China (Yunnan).

Etymology. The specific epithet of this species is derived from the Latin triangulatus (triangular), in reference to the large triangular juxta.

\subsection{Key to Lateantenna species from Mainland China based on male genitalia}

1 Basal spine-like projection longer than valva

- Basal spine-like projection shorter than valva

2 Phallus nearly as long as valva (Fig. 7a)

L. camelliae

- Phallus distinctly shorter than valva (Fig. 7b)

L. ianella

3 Juxta with median portion membranous 4

- Juxta sclerotized 6

4 Upper division of valva with basal $2 / 5$ heavily sclerotized ventrally and forming a narrow band (Fig. 6a) L. zhejiangensis sp.n.

- Upper division of valva not sclerotized ventrally

5 Basal spine-like projection reaching distal 3/7 of lower division (Fig. 6c) L. brevicornis

- Basal spine-like projection reaching distal 1/6 of lower division (Fig. 6b) L. spiniharpella

6 Gnathos without dentitions medially on posterior margin (Fig. 6e) L. semicircularis sp.n.

- Gnathos with two dentitions medially on posterior margin

7 Apical process of lower division of valva bifurcate at apex (Fig. 6d) L. decolor

- Apical process of lower division of valva not bifurcate at apex

8 Lower division of valva with a triangular dorso-apical process (Fig. 7c) L. lunata sp. n.

- Lower division of valva without a dorso-apical process

9

9 Juxta bandlike(Fig. 7d) L. eurotella

- Juxta triangular(Fig. 7e) L. triangulata sp.n.

Acknowledgements. We express our cordial thanks to Dr. David Adamski (U.S.A.) for his kind comments and suggestions on the manuscript as well as for providing useful literature. This study was supported by the National Natural Science Foundation of China (No. 31672372).

\section{References}

Adamski, D. 2003: Blastobasinae (Lepidoptera: Gelechioidea: Coleophoridae) of Thailand, Part II. Four new species of Blastobasis Zeller, 1855. - Insecta Koreana 20(1): 1-6. 
Adamski, D. 2010: Order Lepidoptera, family Coleophoridae, subfamily Blastobasinae. - In: van Harten, A. (ed.), Arthropod Fauna of the UAE 3: 525-531. Pensoft Publishers, Bulgaria. 700 pp.

Adamski, D. \& Brown, R. L. 1989: Morphology and systematics of North American Blastobasidae (Lepidoptera: Gelechioidea). - Mississippi Agricultural and Forestry Experiment Station Technical Bulletin 165, Mississippi Entomological Museum No. 1. 70 pp.

Adamski, D. \& Brown, R. L. 2002: New species of Blastobasis Zeller from New Caledonia and Fiji (Lepidoptera: Gelechioidea: Coleophoridae: Blastobasinae). Insecta Koreana 19(2): 137-145.

Adamski, D., Copeland, R. S., Miller, S. E., Hebert, P. D. N., Darrow, K. \& Luke, Q. 2010: A review of African Blastobasinae (Lepidoptera: Gelechioidea: Coleophoridae), with new taxa reared from native fruits in $\mathrm{Ke}$ nya. - Smithsonian Contributions to Zoology 630: 168. doi: https://doi.org/10.5479/si.00810282.630

Adamski, D. \& Li, H. H. 2010: Three new species of Blastobasinae moths from Beijing, China (Lepidoptera: Gelechioidea, Coleophoridae). - SHILAP Revista de lepidopterologia 38(151): 341-351.

Amsel, H. G. 1968: Zur Kenntnis der Microlepidopterenfauna von Karachi (Pakistan). — Stuttgarter Beiträge zur Naturkunde 191: 1-48.

Chen, F. Q., Huang, D. Y. \& Wu, C. S. 2013: Camellia fruit borer, Neoblastobasis camelliae, a new species of Blastobasinae in China (Lepidoptera, Blastobasidae). — Zootaxa 3682(4): 556-562. doi: https://doi.org/ 10.11646/zootaxa.3682.4.6

Heppner, J. B. 1992: Blastobasidae. — In: Heppner, J. B. \& Inoue, H. (eds.), Lepidoptera of Taiwan, Checklist 1(2): 71. Scientific Publishers, Gainesville, Florida. 276 pp.

Kuznetzov, V. I. \& Sinev, S. Yu. 1985: Neoblastobasis gen. n. (Lepidoptera, Blastobasidae) in the fauna of blastobasid moths of the USSR. - Zoologicheskii Zhurnal 64(4): 529-537.

Li, H. H. 2002: The Gelechiidae of China (I) (Lepidoptera: Gelechioidea). - Nankai University Press, Tianjin. 504 pp.
Meyrick, E. 1907: Descriptions of Indian Microlepidoptera. V. - Journal of the Bombay Natural History Society $18: 137-160$.

Meyrick, E. 1916: Exotic Microlepidoptera 1:481-628. Thornhanger, Marlborough, Wilts.

Meyrick, E. 1925: Exotic Microlepidoptera 3: 129-224. Thornhanger, Marlborough, Wilts.

Moriuti, S. 1987: Records and descriptions of Blastobasidae (Lepidoptera) from Japan. - Tinea 12 (Suppl.): $168-181$.

Ohshima, I. 2013: Blastobasidae. - In: Hirowatari, T., Nasu, Y., Sakamaki, Y. \& Kishida, Y. (eds.), The standard of moths in Japan 3: 249-251. Gakken Education Publishing, Tokyo. 359 pp.

Ohshima, I., Sakamaki, Y., Inoue, H., Arai, T. \& Adamski, D. 2018: DNA Barcoding and adult morphology reveals an unrecorded pest species on Citrus and other new host associations in the Blastobasidae (Lepidoptera: Gelechioidea) in Japan, with taxonomic notes on the genus Lateantenna. — Lepidoptera Science 69(1): 19. doi: https://doi.org/10.18984/lepid.69.1_1

Park, K. T. \& Adamski, D. 2017: The discovery of Syncola beljaevi Sinev, 2007 (Lepidoptera, Gelechioidea, Blastobasidea) from Jeju Island, and a revised check list of the family in Korea. - Journal of Asia-Pacific Entomology 20: 1130-1133. doi: https://doi.org/ 10.1016/j.aspen.2017.07.014

Park, K. T., Kim, M. \& Byun, B. K. 2014: Anew and an unrecorded species of the genus Neoblastobasis Kuznetzov \& Sinev (Lepidoptera: Blastobasidae), with a tentative catalog in Korea. - Journal of Asia-Pacific Biodiversity 7: 233-236. doi: https://doi.org/10. 1016/ j.japb.2014.06.003

Robinson, G. S., Ackery, P. R., Kitching, I. J., Beccaloni, G. W. \& Hernández, L. M. 2010: HOSTS - A database of the world's lepidopteran hostplants. - Natural History Museum, London. URL http://www.nhm.ac.uk/ hosts. (Site visited on 24 March, 2017)

Sinev, S. Yu. 2014: World catalogue of blastobasid moths (Lepidoptera, Blastobasidae). - Zoological Institute of the Russian Academy of Sciences, St. Petersburg. $108 \mathrm{pp}$. 